Onkologie 1990;13:81

\title{
Impressum, Vol. 13, No. 2, 1990
}

\section{Herausgeber}

\section{S. Karger}

Verlag für Medizin und Naturwissenschaften GmbH, Postfach 1724, D-8034 Germering

Presserechtlich verantwortlich: Walter Kunz, Gesellschafter

Offizielles Organ

der Deutschen Gesellschaft für Hämatologie und Onkologie, der Österreichischen Gesellschaft für Hämatologie und Onkologie, der Österreichischen Krebsgesellschaft-Krebsliga

unter Fortführung der «Österreichíschen Zeitung für Onkologie»

\section{Schriftleitung}

J.H. Holzner, Wien W. Queißer, Mannheim

Wissenschaftlicher Beirat

H.W. Bauer, Berlin; V. Diehl, Köln; P. Drings, Heidelberg; E. Dühmke, Göttingen; S. Eckhardt, Budapest; H. Ehrhart, München; H.H. Fiebig, Freiburg; A. Gläser, Halle; E.H. Graul, Marburg;

R. Hartenstein, München; K. Havemann, Marburg; H. Heimpel, Ulm; K.P. Hellriegel, Berlin;

Ch. Herfarth, Ulm; H.W. von Heyden, Einbeck; D. Hoelzer, Frankfurt/M.;

J.H. Holzner, Wien;

R.Hünig, Basel;

H.J. Illiger, Oldenburg;

N.Jaeger, Bonn;

W.F.Jungi,St.Gallen;

U.R. Kleeberg, Hamburg;

H.O. Klein, Köln;

B. Kornhuber, Frankfurt/M.;

H. Löffler, Kiel;

U. Mohr, Hannover;

K. Munk, Heidelberg;

G.A. Nagel, Göttingen;

J. P. Obrecht, Basel;

A. Pfleiderer, Freiburg;

K. Possinger, München;

W. Queißer, Mannheim;

H. Riehm, Hannover;

J. Roth, Basel;

E. Scherer, Essen;

H.-J. Schmoll, Hannover;

M. Schroder, Kassel; 
S. Seeber, Leverkusen;

A. Stacher, Wien;

V. Sturm, Köln;

St.Tanneberger, Berlin;

W. Vahlensieck, Bonn;

M. Wannenmacher, Heidelberg;

W. Wilmanns, München;

K. Wilms, Würzburg;

K. zum Winkel, Heidelberg;

W. Wrba, Wien.

Die Zeitschrift erscheint zweimonatlich; pro Jahr erscheint 1 Band zu je 6 Heften. Bezugspreis für Jahrgang 13, 1990, DM 148,- I öS 1036,- I SFr 116,-. 1 Einzelheft kostet DM 28,- I öS 196,- I SFr 22,-, einschließlich MwSt., zuzüglich Postgebühren.

Der Abonnementpreis ist im voraus zahlbar. Das Abonnement der Zeitschrift läuft weiter, wenn es nicht spätestens 4 Wochen vor Abschluß eines Bandes abbestellt wird.

Abonnementbestellungen können bei jeder Buchhandlung oder direkt beim Verlag aufgegeben werden:

Bundesrepublík DeutschlandlÖsterreich: S. Karger GmbH, Postfach 1724, D-8034

Germering/München, Telefon: (089) 843035, Telex: 524865 D, Telefax: 8418083, Postgiro:

München 40080-807 Schweiz: S. Karger AG, Allschwilerstr. 10, Postfach, CH-4009 Basel, Tel.: (061) 3061111, Telex 62652 CH, Telefax (061) 3061234

Anzeigen

S. Karger Verlag für Medizin und Naturwissenschaften GmbH, Postfach 1724, D-8034

Germering, Telefon (089) 843035. Gültig ist die Preisliste Nr. 5 vom 1.10.1986.

Für den Inhalt außerhalb des redaktionellen Teiles (insbesondere Anzeigen,

Industrieinformationen, Pressezitate und Kongreßinforma-tionen) übernehmen Schriftleitung,

Beirat und Verlag keine Gewähr.

Eine Markenbezeichnung kann warenzeichenrechtlich geschützt sein, auch wenn bei ihrer Verwendung in dieser Zeitschrift das Zeichen ${ }^{\circledR}$ oder ein anderer Hinweis auf etwa bestehende Schutzrechte fehlen sollte. Für Satzfehler, insbesondere bei Dosierungsangaben, wird keine Gewähr übernommen.

Die Zeitschrift sowie alle in ihr enthaltenen einzelnen Beiträge und Abbildungen sind urheberrechtlich geschützt. Jede Verwertung, die nicht ausdrücklich vom Urheberrechtsgesetz zugelassen ist, bedarf der vorherigen Zustimmung des Verlags. Das gilt insbesondere für Vervielfältigungen, Bearbeitungen, Ubersetzungen, Mikroverfilmungen und die Einspeicherung und Verarbeitung in elektronischen Systemen. Fotokopien dürfen nur für den persönlichen Gebrauch als Einzelko-pien hergestellt werden. Jede im Bereich eines gewerblichen Unter-nehmens zulässig hergestellte oder benutzte Kopie dient gewerblichen Zwecken gem. § 54(2) UrhG und verpflichtet zur Gebührenzahlung an die Verwertungsgesellschaft WORT, Abt. VG

Wissenschaft, Goethestraße 49, D-8000 München 2.

(C) Copyright 1990 by S. Karger

Verlag für Medizin und Naturwissenschaften GmbH

Postfach 1724

D-8034 Germering 
Satz und Druck: Walter Biering GmbH Grafischer Betrieb Freisinger Landstraße 21 D-8000 München 45 (BRD)

KAKGEK 